\title{
Underlying Factors Contributing To Presenteeism And Absenteeism
}

Tammy Prater, Alabama State University, USA

Kim Smith, Alabama State University, USA

\begin{abstract}
Modern workplaces must learn how to respond effectively to two trends which can cost employers billions of dollars each year in lost productivity: presenteeism and absenteeism. In 2010, the annual cost of presenteeism, $\$ 180$ billion, surpassed the cost of absenteeism, $\$ 118$ billion (Weaver, 2010). According to the American Heritage ${ }^{\circledR}$ Dictionary of the English Language (2006), presenteeism is defined as "the practice of coming to work despite illness, injury, anxiety, etc., often resulting in reduced productivity". According to Dictionary.com Unabridged (n.d.), absenteeism is defined as "habitual failure to appear, especially for work or other regular duty". In the past, the main attributable factor for presenteeism and absenteeism was workers being sick; however, this research uncovered other underlying causes for this phenomenon. In addition, this research expanded the existing research and found other ways employees cost employers in lost productivity, one of which included conducting personal business during working hours. The research concluded, through the use of Chi-Square tests for independence, there was dependency between some of the variables.
\end{abstract}

Keywords: presenteeism; absenteeism; work productivity; medical condition; co-morbidites; stress; anxiety; worklife balance

\section{INTRODUCTION}

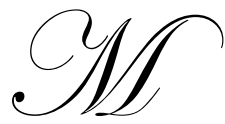

odern workplaces must learn how to respond effectively to two trends which can cost employers billions of dollars each year in lost productivity: presenteeism and absenteeism. In 2010, the annual cost of presenteeism, $\$ 180$ billion, surpassed the cost of absenteeism, $\$ 118$ billion (Weaver, 2010). According to the American Heritage ${ }^{\circledR}$ Dictionary of the English Language (2006), presenteeism is defined as "the practice of coming to work despite illness, injury, anxiety, etc., often resulting in reduced productivity". According to Dictionary.com Unabridged (n.d.), absenteeism is defined as "habitual failure to appear, especially for work or other regular duty". In the past, the main attributable factor for presenteeism and absenteeism was workers being sick; however, this research uncovered other underlying causes for this phenomenon. In addition, this research expanded the existing research and found other ways employees cost employers in lost productivity, one of which included conducting personal business during working hours. The research concluded, through the use of ChiSquare tests for independence, there was dependency between some of the variables.

\section{LITERATURE REVIEW}

This section reviews research on medical conditions and other underlying causes that contribute to presenteeism. It also examines if these causes, such as stress, anxiety, financial status, and others, have a negative effect on both work productivity and employee health. Presenteeism, as indicated in previous research, is the antithesis of absenteeism. It is when an employee believes he/she "must show up for work, even if one is too sick, stressed, or distracted to be productive; the feeling that one needs to work extra hours, even if one has no extra work to do" (Middaugh, 2007, p.172). Employees choosing to attend work, while feeling debilitated because of an illness, have a tendency to put, otherwise, healthy employees at risk. An unhealthy workforce costs the company in the form of lost profits; as once exposed to contagious contaminants, "these newly infected employees will elect to deal with their illness through either absenteeism or presenteeism" (Weaver, 2010, para.4). 


\section{MEDICAL CONDITION AND WORK PRODUCTIVITY}

Prolonged exposure to stress, whether positive or negative, can cause health problems, such as severe headaches, stomach issues, chronic back pain, neck pain, and depression. For many employees, who suffer with emotional and physical stress, it is difficult to perform well on the job. If not managed properly, "stress creates pressure on individuals and families" causing an individual to become easily agitated and less likely to exhibit emotional control (Kim, Sorhaindo, \& Garman, 2006, p. 460).

One survey, geared towards gauging the mental health of Americans, found depression to be significantly high among Americans ages 15 to 44 and adults 40-59 were inclined to experience the most depression (Rankin, 2010). According to Rankin (2010), "depression cost the United States $\$ 83$ billion a year. Nearly two-thirds of this $\$ 83$ billion is from lower productivity and workplace absenteeism" (para.1). In a survey conducted by the Centers for Disease Control, it was reported that "more than 1 in 20 people in the United States are depressed, and of those, 80 percent say their depression interferes with their ability to work" (Rankin, 2010, para.4). Individuals suffering from depression have a difficult time staying focused and performing adequately on the job. This will inevitably translate into higher costs for employers (Rankin, 2010). Unfortunately, employers do not endorse depression screening programs "because of the uncertainty of the return-on-investment of such programs" (Miller, 2007, para.1). Whether employees choose to suffer from depression in silence while at home, or come to work not functioning at their best, employers are reaping the costs of these non-productive patterns of behavior. Employers "spend about 17 percent of its employee compensation budget on costs related to employees not working" (Cyboran \& Morrison, 2006, para.1). Every year disability-related costs, for most organizations, according to a report by Thomas Reuters, are on average " $\$ 1,038$ for depressed people and only $\$ 325$ for non-depressed people" (Rankin, 2010, para.4).

Employers must become more familiar with their employees and the health conditions which deplete company resources and potential profits. Miller (2007) reported, "A new study published in the Journal of the American Medical Association (JAMA) finds that a cost-effective approach to identifying and treating depressed employees, through telephone counseling resulted in higher job retention, decreased sickness, lower work-absence and increased work productivity" (para. 2). Co-morbidites, employees who suffer habitually from a combination of illnesses, cause companies the most in productivity losses (Miller, 2009). The difference between the cost associated with male and female co-morbidites may vary slightly. For example, Duke University researchers examined data from two health related surveys, one in 2006 and the other in 2008, and determined that the costs per person of those who suffer from obesity are as much as $\$ 16,900$ for women and $\$ 15,500$ for men. In addition, presenteeism, among full-time obese workers, proved to be a major expense for employers with costs ranging up to $\$ 73.1$ billion: 56 percent for women and 68 percent for men (Preidt, 2010, para. 10). Ann Wolf, an instructor at the University of Virginia's School of Medicine, whose specialty is in researching the financial impact of obesity, believes that there is an "independent effect of diabetes on employee productivity" (Preidt, 2009, para. 6). In 2009, the American Journal of Health Promotion surveyed 7,338 working adults and established that individuals suffering from "obesity and Type 2 diabetes lost 11 to 15 percent of work time or 5.9 hours of lost productivity per week" (Preidt, 2009, para.2). On the other hand, employees of normal weight had only "9 percent of work time or approximately 3.6 hours of lost productivity per week" (Preidt, 2009, para.2). In addition, the survey revealed obese people with Type 2 diabetes proclaimed that performing simple activities caused them to become weakened 20 to 30 percent of the time. Thus, it is in the employer's best interest to provide programs that curtail the negative effects of poor health within its workforce. According to a recent study by the Strategies to Overcome and Prevent Obesity Alliance, over 500 benefits managers and 1,352 employees agreed that it is appropriate for weight management issues to be addressed in the workplace and " 80 percent of employees, regardless of weight, agree that healthy lifestyles and weight management programs belong in the workplace" (Wells, 2010, para. 3).

Over the years, research studies have confirmed that individuals coping with diabetes and obesity perform at a decreased efficiency. However, employees suffer from other debilitating health conditions, such as stress, anxiety, arthritis, menstrual cramps, and migraines, which can also financially drain employers' resources and result in lost productivity. The impact of illness can affect anyone in an organization. Miller (2009) noted, "Executives and managers seem to suffer high presenteeism productivity-loss related to specific health conditions along with those in non-managerial jobs" (p. 20). 
Stress is ubiquitous and not only surfaces in one's personal life, but is indigenous in organizational life today. According to Greenberg (2011), over "90 percent of American workers report feeling stressed at least once per week, and 40 percent describe their jobs as very stressful most of the time" and "in fact, about half of all American workers report that stress has adversely affected their health" (p.155). As the jobless rate increases and corporations deliberately prolong the rehiring process; survivors of corporate massive layoffs are concerned about work pile up and fear being laid off. The effects of insurmountable stress are injurious to the individual and expensive for the organization (Greenberg, 2011, p.155). Such high levels of stress can cause workers to become mentally distracted and disengaged in work activities. Fear of job loss may preempt employees from taking much needed days off when they are feeling sick or emotionally overwhelmed. Thus, presenteeism evaluates the "decrease in productivity for the much larger group of employees whose health problems have not necessarily led to absenteeism and the decrease in productivity for the disabled group before and after the absence period" (Schultz, Chen, \& Edington, 2009, p. 366).

The inability to function with clarity on the job, which is another form of presenteeism, may be customary for chronic migraine sufferers. Researchers believe that the true economic cost of migraines has not been fully assessed; since most people who suffer from migraines have not been clinically diagnosed. Two research studies presented at the 2009 International Headache Congress in Philadelphia revealed "that people with 15 or more migraine attacks per month lost approximately 4.5 hours of work productivity a week" (Boyles, 2009, para. 4). To explain this phenomenon further, researchers surveyed over 500 people to elucidate the impact of migraines on employee productivity and discovered most workers forced themselves to go to work in distressed conditions. The University of Tennessee's Medical School partnered with drug manufacturer GlaxoSmithKline to conduct a survey of 509 migraine sufferers. "The patients stated that 11 percent of workday migraines resulted in a full day of work lost, while only 5 percent led to late arrivals to work and 12 percent led to early work days" (Boyles, 2009, para. 12). Unfortunately, 62 percent of the time, employees suffering from intense migraine pain opted to remain at work at a decreased productivity rate of possibly 25 percent during these times (Boyles, 2009). Migraines, according to Fred Sheftell, MD, president of the American Headache Society, cost American businesses over \$24 billion annually in medical bills and poor productivity (Boyles, 2009).

Managers that create a competitive culture, where employees are expected to work long hours and assume projects, which require constant attention, may be unaware of the underlying pressures that force employees to come to work not feeling well. According to a survey conducted by the staffing service Office Team, there appeared to be a disconnection between employees and their managers when it came to defining what constitutes "not feeling well". Out of the 522 American workers surveyed, 45 percent said they "very frequently" go to work when they are sick; however, only 17 percent of their bosses actually thought they did so. Likewise, even when 30 percent of employees attended work "somewhat frequently" feeling ill, more than half of the executives failed to recognize they did (Gurchiek, 2009).

\section{UNDERLYING CAUSES FOR PRESENTEEISM NOT RELATED TO MEDICAL CONDITIONS}

As employees fear job loss and reprimands for excessive time off, they are more than likely to conduct personal business while at work. A survey conducted for Cigna in May 2008 found that there was an average of approximately seven days of presenteeism per employee during that month, even though employees were present, they were more focused on personal business rather than job-related tasks (Gurchiek, 2009). For example, even during the height of the swine flu epidemic, $71 \%$ of American workers were more likely to go to work because they feared job loss or did not want to miss a deadline at work (Immen, 2009). Thus, presenteeism can affect healthy employees when they are more focused on personal issues, such as their talking with teachers concerning a child's school performance, setting up doctor's appointments for family members or themselves, and solidifying quality care for an aging parent. These non-related medical issues can consume 2.4 hours per week of an employee's work time (Gurchiek, 2009).

\section{UNDERLYING CAUSES FOR STRESSOR AND ANXIETY}

Americans push themselves to attain the "American Dream" despite the financial crisis, even when concerns of obtaining economic stability are overwhelming. Kim et al. (2006) discovered "60 percent of working 
Americans, who are employed by a company that offers a retirement plan, indicated that they were experiencing moderate to high levels of financial stress" (p.460). Most workers living in the current devitalized economy experience challenges making, the smallest, monetary obligations. Many Americans, affluent and poor, have felt the strain of financial stress. Stressors related to long hours spent on the job, surmounting expenses piling up pursuant to job losses, increased credit card debt, fierce local and global competition, and the desire for work-life balances can be manifest into incapacitating diseases and lost work productivity.

Based on an interview by Office Team in 2009, a group of office workers over the age of 18 and 150 senior executives were polled, more employees are feeling pressured to come to work in the current economy, because they do not want to be "out-of-sight, out-of-mind" (Gurchiek, 2009, para.6). This is especially prevalent among women working full-time who, despite years of progress, "only earn 80 cents to every dollar earned by the average full-time working man" (U.S. Congress Joint Economic Committee, 2010, p.1). For most women, keeping their jobs during a recession is problematic. Lean workforces affect women, whom typically lead single family households, more as they may be terminated first. In 2009, women were heads-of-households for approximately 9.8 million families and were the primary caregivers of children, ages 18 and under (U.S. Congress Joint Economic Committee, 2010). Further, over the past four years, "female workers have lost 298,000 jobs" and "unemployment for them rose from 4.1 percent in 2000 (the yearly average at the time) to 5.2 percent in July 2008" (Gurchiek, 2008, para. 3). As evidenced in health insurer Bupa's report, women suffer sleepless nights over "financial fears and anxiety over their personal and family's health" and "almost 50 percent said they were stressed in their everyday lives compared with 4 out of 10 men" (Paton, 2008, p.5).

Bupa's poll also discovered "that among those worried about their job security, 40 percent felt their stress levels had increased at work since the financial crisis began, while almost 25 percent claim now to be working longer hours to ward off the risk of losing their job" (Paton, 2008, p. 5). Years of ostentatious spending may have caught up with Americans in general. A national survey confirmed that "52 percent of employees manage their finances by living paycheck-to-paycheck" (Kim et al., 2006, p. 460). Family obligations, limited financial resources, and the dependency on each paycheck, strongly influences many Americans to trudge to work sick; which, not only jeopardizes recovery time, but puts their fellow coworkers at risk ( "Sick time means a healthier," 2009).

Despite Congress' endeavors to provide universal healthcare, many corporations do not share in its enthusiasm. According to "Sick Time Means a Healthier Economy" (2009), more than 50 percent of all private sector workers and 79 percent of all low-wage earners are not offered paid sick time off by their employers. In the November 24, 2010, issue of What's Working in Human Resources, several large firms would rather pay the government penalties than offer "worker health insurance under the new reform laws" that to them "doesn't make financial sense" ("One-third of firms to cut healthcare costs," 2010, p.1). Furthermore, a national survey, conducted by Grant Thornton, LLP, discovered that 30 percent of U.S. CFOs and senior comptrollers plan to decrease the number of health care benefits offered to their workforces. Twenty-three percent of them will slice bonuses, and another 18 percent agreed to eliminate some stock options/equity based compensation ("National Survey of U.S. CFOs," 2010). Without decent health insurance and living in economic distress, employees, particularly low-wage earners, are more likely to determine if the effects of an illness can be tolerated, and based on how sick they feel, will go to work. However, many in the field believe "Being able to take a day off when sick should not be a luxury reserved for those who work in shops with a beneficient employer. Paid sick days serve the public health, the bottom line and promote decent working conditions" ("Sick time means a healthier economy," 2009, p. 2).

For some employees, attending work ill may have more to do with a sense of duty than because of financial strain or lack of personal or sick leave. Several employees attend work because they do not want to disappoint their team members. According to Gurchiek (2009) "two-fifths of workers attributed their work ethic, dedication or a belief their company/co-workers needed them for going to work despite feeling ill or having other issues while only one in four did so because they needed the money" (para. 14). Managers must be cognizant of the hidden messages sent to employees with regard to workplace norms and expectations. Office Team's Britton observed that when employees watch their managers work sick; they are less likely to take sick leave when they are not well. Managers, can attempt to create a healthy work environment by encouraging employees to take leave and remain home when they are not feeling well. This can be done by "setting an example" and "communicating expectations that they prefer employees stay home when sick to ensure a quicker recovery and lessen the likelihood of spreading 
contagious illnesses, such as colds and flu" (Gurchiek, 2009, para. 18).

Economic pressures, coupled with expanding workloads, compel managers to place extraordinary pressures on their staff to perform. In a recent interview at the "Tulsa Business Forum: An Interview with Jack Welch," sponsored by Oklahoma State University's Spears School of Business on February 23, 2011, Mr. Welch admonished corporations to remain focused on profits by stating, "If it doesn't turn green into green, it doesn't turn out to be a helluva good business," Welch said. "The whole idea is to grow jobs. The main social responsibility for a company is to win" (Walton, 2011, para. 24). In the current corporate climate, employees are constantly reminded to do much more with less. Even Mr. Welch believes that underperforming workers, who are unable to adapt to highly competitive environments, should be fired. In his interview, Welch stated, "We played business like it was a sport," and "You make a game of it, you field the best team and weed out the weakest" (Walton, 2011, para. 8). "The weeds you've got to pull out if you're going to build a beautiful garden" (Walton, 2011, para. 9).

Results from surveys by Friends Provident Insurance Firm and the National Stress Awareness Day, revealed that 25 percent of adults are prepared to work longer hours over the next 6 months and 12.5 percent expected to take on another job (Paton, 2008). As stress and anxiety become the standard attribute of what used to be characterized as a "normal work environment", 66 percent of employees "said they felt more stressed, run down, and prone to illness than they did three years ago, with 10 percent, specifically, blaming their work, bosses, and colleagues" (Paton, 2008, p. 5). Oftentimes, the effects of stress can be seen by others; however, according to Bruce Tyson (2010), managers should be more concerned about how stress can affect worker attitudes as poor attitudes "fundamentally undermine any positive aspects of the work environment and generally results in hostility" (para. 9). Employees feeling overwhelmed by stress will often develop negative feelings about almost anything associated with their employer (Tyson, 2010). These feelings are also apparent in global corporations. A Workplace Stress Survey of Britons, working for the government, showed, "a disproportionately high $90 \%$ of respondents felt stress was a workplace problem, $63 \%$ said they did not feel their staff trusted the people at the top, compared with the overall survey average (28\%), and only $35 \%$ said their people 'have a lot of laughs at work' compared with the average of $42 \%$ " (Clements, 2008, para.19).

Thus, the creation of a healthy work-life balance has become a universal problem for employees. "In the current economic environment, work-life balance now ranks as one of the most important workplace attributessecond only to compensation, according to research conducted by the Corporate Executive Board (2009) among more than 50,000 global workers. And employees who feel they have a better work-life balance tend to work $21 \%$ harder than those that don't" (para. 2). Unfortunately, many employers avoid fulfilling this need as they strive to remain competitive. The Corporate Executive Board (2009) also reported, "In 2006, 53\% of employees felt they had a good work-life balance; that number fell to $30 \%$ in the first quarter of 2009" (para.3). Despite favorable reports from health care experts who indicate companies which have "implemented wellness programs are starting to see the first real ROI on their investments - mainly in the form of decreased healthcare costs"; many employers are not willing to wait 18 months to see the benefit of such programs (Bilski, 2008, para.3).

In an attempt to uncover an assortment of workplace issues from the employees' perspective, the Society for Human Resource Management (2009) asked U.S. employees in an Omnibus Employee Survey to answer several questions concerning the pressure they feel, whether perceived or real, within the past year to stay "connected" to the workplace, even when they are not obligated to work. The employees' selection of the "frequent" response showed that 25 percent checked e-mail while on vacation, 26 percent checked e-mail while taking sick leave, and 36 percent checked work e-mail after hours. After hours is considered work beyond scheduled time during the week or the weekends. The survey also segregated responses by differences in employee level. This showed "executive-level and middle-management employees disclosed that they had a greater average frequency compared with nonmanagement employees for 1) working after hours, 2) checking work e-mail after hours, 3) checking e-mail while on vacation, 4) checking e-mail while taking sick leave and 5) working through their lunch break" (p. 4).

Interestingly, the response to the question "In your current job, which of the following are the main sources of pressure to work after hours" showed the top three reasons were 1) self-imposed pressure, 2) meeting project or performance goals, and 3) pressure from immediate supervisor or/manager. Furthermore, 62 percent of middlemanagement employees versus 44 percent of non-management employees report self-imposed pressure; whereas, 23 percent of executive-level employees versus 6 percent non-management employees report pressure due to demands 
from people who support or invest in the organization and only 12 percent of non-management employees versus 3 percent of middle-management employees report other pressures (Society for Human Resource Management, 2009, p. 9).

As managers aim to meet shareholders' expectations during these economic times, the ability to disconnect mentally from the job is becoming exceedingly difficult. In a recent survey by CareerBuilder, even healthy employees have a tendency to call in sick when they are actually well. The survey revealed that more than 25 percent of firms asserted workers "call out sick with fake excuses because they are stressed or burned out by the economy" ("More workers call out sick when they're well," 2010, p.6). As a result, companies are developing health and wellness programs to be proactive in helping employees manage the life stressors that have become customary in U.S. workplaces. It is for this reason, that "most employers $(68 \%)$ have four or more programs in place to help workers deal with stress, and $22 \%$ of companies offer eight or more stress-relief programs for workers" (Bilski, 2010, para. 2). Workers must learn to identify job stressors that cause them to become physically sick or mentally drained. EAPs (Employment Assistance Programs) are the primary resource that companies use to provide support to its employees and 78 percent of those surveyed stated that they had it in place (Bilski, 2010). Companies are acknowledging their role and responsibility towards the mitigation of stress among its workers. Thus, "63 percent of companies provide flexible work schedules, 46 percent offer work-life balance support programs, and 45 percent make leadership training available on worker stress" (Bilski, 2010, para.6).

Like the United States, England also faces challenges controlling employee stress. Stress and mental health issues account for 40 percent of absenteeism. Managers, who fail to offer mental health programs that support distressed employees when they return to work, may lose them, "as they often turn into the long-term 'unworkable' population" (Clements, 2008, para. 2). Ingolve Urnes, CEO of Active Health Partners (AHP), attempts to address stress incidents more quickly by establishing a process of intervention for employees who fail to contact the nursing center following a sickness absence (Clements, 2008). In addition, resilience to stress has become a major factor in how employees react to and manage stress. Drew Fobbester of MyVitality.com, an online resilience profiling company stated that, "The more healthy a person is, the more resilient to stress they will be" (Clements, 2008, para. 17). My Vitality's corporate clients were able to achieve a 10 percent 'vitality rating', based on a thorough questionnaire that assessed quality-of-life and productivity, and retention rates rose to 80-85 percent (Clements, 2008).

Physicians have long been advocates of eating well and engaging in daily exercise as possible combatants to stress, anxiety, diabetes, high blood pressure, and early signs of depression. In January 2008, Let's Get Healthy conducted an analysis of 327 office workers and discovered a significant difference between those who became easily stressed from those who felt they could cope. The results showed that people who were quickly stressed had higher levels of absenteeism than those who possessed hardy personalities (Clements, 2008). However, in another study, 68 percent of employers polled said that work-life balance was a significant producer of stress and only 38 percent of them said they were engaging in activities that would help them combat the effects of stress (Wojcik, 2009). Manhattan psychologist Dr. Joseph Cilona believes that employees can recover from stress and regain a sense of normalcy if they are willing to acknowledge that have a problem. Cilona suggests that employees use the following steps: 1) educate themselves about stress and use tactics that work for them, whether it involves a change in routine, counseling, or holistic treatment, 2) ask others if they have noticed a change in one's behavior, 3) avoid being ashamed by the stigma and seek the assistance of mental health professionals, who are trained to assist employees with their fluctuating moods and stress levels, 4) take a proactive approach to dealing with mental health needs and welcome different approaches that can solve one's problems (Goodman, 2010, para. 7).

\section{PERSONAL BUSINESS CONDUCTED DURING OFFICE HOURS AND ABSENTEEISM}

According to Middaugh (2007), "a report in Risk \& Insurance indicated that the root causes of presenteeism are not always medical. They frequently include issues of childcare, financial worries, addiction, divorce, or family problems. Boston.com recently reported that many women are one sick child away from losing their jobs" (Middaugh, 2007, p.172). Family obligations also cause employees to miss work and employers should allow flexible scheduling as an option. In 2010, claims related to FMLA (Family Medial Leave Act) increased by more than 10 percent because of personal illness/injury, caring for a child and/or elderly relative ("FMLA claims rise by more than $10 \%$ in 2010," 2010 , p.6). 
Absenteeism, according to the article "Introduction to Attendance Management" (2010), "is the failure of employees to report for work when they are scheduled to work" ("Introduction to Attendance", 2010, para. 5). This would exclude "employees who are away from work on recognized holidays, vacations, or approved leaves of absence" ("Introduction to Attendance", 2010, p.1). In Canada, each time an employee is absent, the employer loses "an average of $\$ 2,500$, which includes both direct and indirect costs (based on 9 days absent out of 250 working days and an average payroll of \$35,000)" ( "Introduction to Attendance", 2010, para. 3). The cost of absenteeism, according to Middaugh (2007), "is easy to calculate: 100 percent of the worker's productivity is lost each day that the worker is not on the job" (p.172). Therefore, companies need to be able to track both direct and indirect costs associated with absenteeism. According to Hall (2010), employers can use tracking programs to limit unscheduled time away from the job and objectively manage work productivity. The systems may be used as a prevention tool that not only "helps keep employees on the job, but it keeps them connected to the right support resources" (Hall, 2010, para. 8). Since the cost of absenteeism exceeds the "payment of wages and benefits paid during the absence", employers must consider the "indirect costs of staffing, scheduling, re-training, lost productivity, diminished moral, turnover, and opportunity cost. The indirect costs often exceed the direct cost of absenteeism" ("Introduction to Attendance", 2010, para. 2).

\section{FACTORS AFFECTING PRODUCTIVITY}

Loyalty, engagement, and trust continue to decline despite employer efforts to help employees cope with the economic meltdown and internal changes. According to a report by Watson Wyatt Worldwide and the National Business Group on Health, although health and productivity management programs have been able to minimize health care cost and decrease absenteeism, most employers have failed to develop procedures that will assuage the stress of mandatory long hours, lack of work-life balance, and fear of job loss. Consequently, management's failure to acknowledge employees' fear of job loss may cause problems as the economy slowly recovers as these stressors are factors that negatively affect productivity. In a recent survey, 67 percent of employers admit that fear of job loss is a leading cause of employee stress, yet only 41 percent of employers said they are addressing the issue (Wojcik, 2009).

In a [video interview with Sylvia Ann Hewlett, founder of The Center for Work-Life Policy's], Susan Berfield, associate editor of Business Week, discussed the anxiety felt by employees after the recession. Hewlett's book "Keeping performance up when businesses are down" researched seven Wall Street and seven Main Street Companies. She discovered that the office climates had changed and there was a rapid decline in trust and engagement among the remaining employees. According to Hewlett, 73 percent of employees stated they felt managers gave them little or no attention. She also stated that "in the wake of massive layoffs, 35 percent of survivors walk out the door", which means the top performers are leaving companies as soon as an opportunity presents itself.

The problem, according to Hewlett, is that CEOs are more concerned about clients than retaining his or her best performers. During the interview, Hewlett shared that one employee stated that "I have left the job, but I haven't quit". Thus, managerial neglect may also be a determining factor of employee presenteeism. Prior to the recession, 95 percent of the people Hewlett interviewed said they were very loyal to their employer, in 2008; that number had plummeted to 53 percent. Trust was also negatively affected after the recession, as it went from 79 percent to 37 percent. Employees who were forced to witness the laying off of top performers believed that the rules were no longer valid, thus engagement - the willingness to work and perform beyond what is required - decreased by 20 percent. In the wake of a dilatory economy, Hewlett suggested that managers intervene and become more accessible by building camaraderie with team members. She also warns of high voluntary attrition and how companies may suffer because of them. Similarly, a center for Work-Life Policy survey shows that between June 2008 and January 2009, 14 percent of college graduates lost their jobs - of these, 32 percent were fired; however, 68 percent voluntarily quit (Berfield, n.d.). 


\section{METHODOLOGY}

After an initial review of the literature pertaining to absenteeism and presenteeism, an anonymous survey was given to students and faculty members at a historically black university. The participants were asked to answer questions pertaining to their full or part-time job. For this research, there were 138 useable surveys. The participants were asked to answer a series of "yes" and "no" questions, categorical questions, and ranking questions.

The questionaire was divided into six different sections. The first section of the questionaire collected demographic information. The participants were asked questions pertaining to gender, age, race, marital status, number of children, level of education, employment status, annual income, type of employment, and number of employees at the firm. Statistical analysis will be used to determine if there were any differences based on gender, age, or education level in the response rate as it pertains to absenteeism/presenteeism. The statistical analysis will reveal if there were any relationships between annual incomes, the number of employees at the firm, whether the person was self-employed and how often they had occurrences of presenteeism.

The questionnaire also covered areas pertaining to the overall health status of those being surveyed. The participants were given a list of common medical conditions, such as diabetes, depression, obesity, migraines, and anxiety/stress, and asked to respond if they had that condition. Next, the respondents were asked if their medical condition affected their productivity levels, how often they went to work sick, were they contagious, did they disinfect their work area, and had they caught an illness from another worker. Statistical analysis will be used to determine if there is a pattern between overall health status and their loss of productivity at work.

Respondents were asked to cite the causes for going to work "Not at Their Peak Level". The participant was given a list of 19 common causes and asked to check all that applied. Some of the reasons listed were: not that sick, needed money, sense of duty, fear of losing job, and did not want to use sick leave. Also, covered in this section were reasons the participant may be experiencing stress and/or anxiety. Since exercising has been shown to reduce stress levels, the questionnaire asked how often the worker engaged in exercise.

Another section addressed conducting personal business during working hours. Workers come to work and spend their workday sending personal e-mails, handling childcare/eldercare problems, scheduling doctor's appointments, handling vehicle purchase/repairs or handling debit/credit problems. Each participant was asked how often they conducted personal business at work, how many hours per day they spent doing these personal items, and last, which type of personal items they handled during business hours. Statistical analysis will be conducted on these categories to see if there is a relationship between gender and each of the above categories. Also, a means test will be conducted to compare the average number of hours per day spent on personal business by each gender.

Sick leave was also studied. The participants were asked how many days per month they miss work and their reasons for missing work. The survey listed ten typical reasons for missing work and the worker was asked to check all that applied. Some of the common reasons listed were: actually sick, going to doctor's appointments, childcare, home repair, and vehicle repair. Statistical analysis will be used to calculate the average number of days missed per month, and to determine the most common reasons workers cite for missing them. A means test will be used to determine if there is a difference in the number of days missed per month based on gender.

The last section of the survey covers other areas that may affect worker productivity and work-life balance. The participant is given a list of seven items that may decrease their productivity. The items included: poor management, organizational changes, lack of defined goals in the job, no longer motivated by the work, and lack of accountability. The participants were also asked "would they turn down a promotion if it required a significant increase in the number of hours" and "if they were willing to work fewer hours for less money." Last, the workers were asked if all of their vacation time was used. The researchers wanted to gauge if the workers were causing themselves undue stress and a shift in their work-life balance by not using all of their available vacation time. 


\section{RESULTS}

SPSS was used to conduct the statistical analyses. The means were calculated for all ratio data, frequency charts were constructed for all categorical data, and pivot tables were constructed to run the Chi-Square tests for independence. This particular study involved over 150 variables.

Of the 138 completed surveys, 59 percent of the respondents were male and 41 percent were female. The average age for the participants was 23, of which, 86 percent were African-American, 7 percent were Caucasian, 2 percent were Hispanic, and 4 percent were other. Ninety-four percent of those surveyed reported they were single, two percent were married, two percent were divorced, and two percent were other. Of the 85 percent that reported having children, 7 percent were the sole provider, 13 percent were partial providers for their children, either living at home or out on their own, and on a surprising note, 10 percent stated they were the sole provider for terminally ill children. Concerning education, 83 percent graduated from high school and are currently attending college, 16 percent had either an Associate's Degree or Bachelor's Degree, and 1 percent held a Doctoral Degree.

Concerning employment, 92 percent were employed by someone else and 8 percent were self-employed. Of those employed, 51 percent were part-time employees, 22 percent were full-time employees, 5 percent were temporary, and 22 percent checked the "other" category. Concerning the type of work the respondents performed , 10 percent were professionals, 9 percent were managers, 6 percent were clerical, 5 percent were in operations, 4 percent were in a technical field, 2 percent were teachers, and last, 64 percent listed other. This "other" category needs to be examined to determine the type of work not covered by those already listed. An explanation could be they were working in a sales or service business.

Annual income was requested of the participants. Seventy-six percent reported making less than $\$ 20,000$, 20 percent reported making between $\$ 20,000$ and $\$ 40,000,3$ percent made between $\$ 40,000$ and $\$ 60,000$, and 1 percent made over $\$ 80,000$, annually.

One of the items viewed as a contributing factor to presenteeism was the number of employees at the firm. The theory was, the smaller the firm, the more pressure placed on each worker to show up for work because there were not any replacement workers to perform extra duties. Forty-nine percent worked with less than 20 employees, 25 percent worked with between 20 and 100 employees, 8 percent worked with between 100 and 500 employees, and 18 percent worked at a firm employing more than 500 employees.

The next set of results addresses overall health status, common medical conditions, and medical conditions effecting productivity. Thirty percent stated their health status over the last twelve months was "Excellent", 57 percent had "Good" health, 12 percent had "Fair" health and last, 1 percent chose "Poor" health.

The respondents were then given a list of common medical conditions and asked to check all that applied. Twenty percent reported experiencing migraines, 12 percent had back and/or neck pain, 10 percent had anxiety/stress, 10 percent suffered from asthma, and 9 percent had severe menstrual cramps. Arthritis was reported by seven percent, depression was listed by five percent, two percent were obese, and heart disease and diabetes were listed for less than one percent each. When asked whether their medical condition affected their work, 91 percent said no and only 9 percent admitted that it did indeed affect their productivity while at work.

When asked how often they went to work sick and why, 12 percent reported "Never" going to work sick, 28 percent "Rarely" go to work sick, 50 percent "Sometimes" go to work sick, and 10 percent "Often" go to work sick. When asked if they were contagious when they went to work sick, 18 percent reported knowing they were contagious and still went to work. Forty percent reported catching an illness from another co-worker. Studies indicate a great source of contamination comes from eating at one's desk. Twenty-six percent reported eating at their desk and a surprising 52 percent, disinfect their work area.

The main initiative behind the survey was to determine some of the underlying causes for presenteeism and/or absenteeism so business leaders could address these areas. If workers continue to go to work sick, their production levels will not only be negatively affected, but they will spread their diseases and affect the total firm's 
production level. To help discover the rationale behind this phenomenon, participants were given a list of 19 reasons for going to work sick and asked to check all that applied. The number one reason the employees listed, at 42 percent, was that they were not sick enough to use a sick day and an additional 17 percent did not want to use their available sick days. However, 11 percent did cite they did not have any sick days left to use. Forty-one percent went to work because they needed money or had some financial obligations to meet. As to the reasons for showing up to work sick, some workers cited a sense of duty (29 percent), not burdening their colleagues (12 percent), and being in a management position and having others report to them (4 percent). Others cited work related reasons, such as to prevent work pile up (16 percent), looming deadlines ( 9 percent), and having meetings already scheduled with clients ( 5 percent). Retaliation was prevalent in some of the next set of responses. Twentyone percent feared losing their job, 18 percent thought they would be viewed as a slacker if they stayed home, 12 percent would be penalized if they stayed home, and 2 percent were still on probationary status. Some workers thought they could not be replaced. They cited responses, such as nobody can do my job (8 percent), could not find a replacement worker (17 percent), and 8 percent stated they were self-employed. The last group of responses suggested it was the corporate culture to come to work sick (1 percent) and others said they must work 50-60 hours per week to be promoted (1 percent).

Since stress can be such a debilitating factor and lead to lost productivity, the survey asked participants to report the underlying causes for their stress and/or anxiety. Work-life balance and overworked accounted for 33 percent and 22 percent, respectively. In this economic time, all employers are trying to get each worker to do more with fewer resources. Twenty-two percent acknowledged family problems, 15 percent had work-related problems, and 17 percent had debit and/or credit problems. The last area, health problems, accounted for seven percent of the respondents. These numbers are especially interesting since only 10 percent cited they had stress and/or anxiety issues and five of the six categories had percentages above the previously stated 10 percent.

Some additional questions were asked to gauge the work-life balance phenomenon. Around 28 percent of the respondents stated they would turn down a promotion if it involved a significant increase in the number of hours worked. However, only nine percent said they were willing to work fewer hours than they currently work. When asked about their use of their vacation time, 38 percent stated they "Never" use all of their vacation time, 20 percent "Rarely" use their vacation, and 19 percent "Sometimes" use all of their vacation time. It is surprising that only 23 percent "Often" use all of their vacation time.

Studies have shown that exercising can be a great stress reliever. So, the participants were asked how many times per week they engage in exercise. Thirty-two percent stated they "Never" exercise, 31 percent exercise once per week, 30 percent exercise 3 times per week, and 7 percent recorded exercising 5 or more times per week.

Since most research on presenteeism has been related to workers going to work not at a peak production level, the researchers wanted to explore other forms of presenteeism. One area of interest was employees working on their personal business during company hours. When asked "How often do you conduct personal business at work", only 39 percent stated they "Never" conduct personal business at work. In contrast, 61 percent of the workers did work on personal business during company hours. Of that 61 percent, 15 percent "Often" work on personal business, 27 percent "Sometimes" work on personal business and 19 percent "Rarely" work on personal business during company hours.

The researchers were curious as to the approximate number of hours per day each respondent spent on personal business. The average number of hours reported spent on personal business was 2.17, with a standard deviation of 1.14 hours. The minimum was zero and the maximum number of hours reported was four. However, men reported an average of 2.33 hours per day, with a standard deviation of 4.64 hours and women reported an average of 1.13 hours per day, with a standard deviation of 2.25 hours. The researchers wanted to ascertain if there was a difference between the number of hours spent on personal business by men and by women. The researchers were very surprised to see that men were spending 1.2 hours more than women per day on personal business $(\mathrm{p}=$ $.05)$.

The researchers were curious as to what type of personal business these workers were conducting at work. Surprisingly, 25 percent reported scheduling doctor's appointments during working hours. The next areas were debit/credit problems (19 percent), vehicle purchase or vehicle repairs (17 percent), childcare ( 7 percent), teacher 
conferences ( 7 percent), and home purchase or home repairs (5 percent). Around one percent cited eldercare, foreclosure, or personal relationships as their reason for using company time for personal business.

The researchers went on to ask the participants as to other causes that might affect their productivity levels. The number one cited cause was "Poor Management", at 51 percent, and an additional 17 percent cited organizational changes as to the cause of their lost productivity. Lack of motivation, defined goals, and accountability accounted for 34 percent, 23 percent, and 18 percent, respectively. Seventeen percent were ready to leave the organization. Surprisingly, eight percent said they felt pressure from management to show up to put in some "Face Time".

Absenteeism has been previously defined as "habitual failure to appear, especially for work or other regular duty" (Dictionary.com, n.d.). The survey participants reported an average number of days missed per month was .94 , with a standard deviation of 1.47 days. The minimum number of days reported was zero, but the maximum number was an astonishingly seven days. However, men reported an average of .82 days, with a standard deviation of 1.4 days and women reported an average of 1.12 days, with a standard deviation of 1.57 days. There was not a statistical difference on the number of days missed per month based on gender.

In order to measure the causes for absenteeism, the participants were given a list of ten reasons for being absent from work and asked to check all that applied. The most common reason, at 51 percent, was actually being sick and right behind it, at 22 percent, was doctor's appointments. Eleven percent of the workers cited personal relationships and 10 percent cited vehicle purchase or repairs. Four percent of the workers were in teacher conferences. Last, around three percent of the workers cited debit problems, eldercare, childcare, home purchase, repairs or foreclosure.

Chi-Square tests of independence were constructed to see if any of variables were dependent upon another variable. In other words, did men typically report to work sick or were women reporting to work sick more often? Below describes the Chi-Square analysis results for the tests that resulted in a dependency with a p-value of less than 10 percent.

Concerning the males, it was confirmed they reported more often than women as being the one financially responsible for the children (.09). They reported their health status for the last 12 months as being "good" (.005). However, they went on to report they either "sometimes or often" go to work sick (.04). The rationale men used for reporting to work "Not at their Peak Level", was one of four reasons: because people reported to them, their sense of duty, to prevent work pile up, and because they were self-employed (.06, .01, .06, and .01, respectively).

Concerning the females, they reported their health status as being either "excellent or fair" (.005). Contrary to the above statement, more females reported having health problems than their male counterparts (.002). Females reported they either "never or rarely" go to work sick (.04). However, when females did go to work sick, they were contagious (.08). Females complained of having migraine headaches more often than men (.028). The rationale women used for reporting to work "Not at their Peak Levels", was one of two reasons: because everybody else in the office reported to work sick, or they did not want to use their sick leave (.08 and .04, respectively).

The last set of Chi-Square tests dealt with dependency and income levels. Respondents in the annual salary range of $\$ 40,000$ and $\$ 59,000$ reported the reason for coming to work sick was because they did not have any sick leave left (.08). This was surprising since the researchers assumed the respondents in the lower salary ranges would be the ones without any sick time left. The respondents in the annual salary range of $\$ 20,000-\$ 39,000$ and $\$ 40,000$ $-\$ 59,000$ reported the reason for coming to work sick was either because they perceived nobody could do their job or because of a sense of duty (.002 and .007, respectively). This was also surprising since the researchers assumed the lower salaried workers would not think anyone could replace them. However, it was confirmed that the higher salaried workers thought they could not be replaced.

\section{FUTURE AREAS OF RESEARCH}

It should be understood that this research does not cover every possible area. It is a starting point. Work is being continued in this area by many authors. The researchers would like to administer the survey instrument to a 
larger population. The larger group would need to include participants from an an older population and workers employed at larger firms. Some of the health problems listed are not typical for a younger population group and more information may be gathered as to how these health problems effect productivity levels. Also, workers at larger firms would have access to larger benefit packages. Employee benefits that would be of importance would be availability of sick leave, paid time off, replacement personnel, and health club memberships. Forty-one percent cited they went to work because they needed the money. However, if the firm offered adequate sick leave, the worker's salary would not be affected by missing days. Also, the researchers discovered other areas not included on the original survey instrument that would have had an impact on productivity levels. These areas are sleep deprivation, pregnancy, lupus, dental, smoking, endometriosis, and allergies.

\section{CONCLUSIONS}

Studies have shown that presenteeism and absenteeism costs employers $\$ 180$ billion and $\$ 118$ billion, respectively (Weaver, 2010). The survey results confirmed that employees are showing up to work consistently sick, stressed, and overworked. In fact, not only were the employees showing up sick; they were doing something far worse. They were contagious and knowingly infected other healthy workers. In addition, employees listed multiple medical conditions that increased the loss of productivity to the firm. The survey also confirmed some of the suspected underlying reasons why the workers came to work not at their peak performance level, such as, did not want to use sick days, looming deadlines, self-employed, and retaliation. Coupled with the above effects, workers were conducting a variety of personal businesses during company hours. An interesting finding was that men conducted personal business 1.2 hours more per day than women. Last, some of the underlying reasons for absenteeism were discovered such as: actually being sick, doctor's appointments, home repairs, and vehicle repairs.

\section{AUTHOR INFORMATION}

Dr. Tammy Prater, Professor of Management, has been a faculty member at Alabama State University since 1997. She has degrees from the University of Alabama (BS - MIS 1989, MA - Production Management 1981, Ph.D. Production Management 1997). Prior to joining Alabama State University, she taught at the University of Alabama and Auburn University Montgomery. She has numerous articles and presentations on work force planning, personnel management, service section planning and published articles in the S.A.M. Advanced Management Journal, CIIMA, and Journal of Contemporary Business Issues.

Kim F. Smith is an Instructor of Management at Alabama State University. She joined the Alabama State's Business faculty in 2006 as an adjunct instructor and later as a non-tenured faculty member in 2008. Kim has 20 years of Human Resource experience and 15 years as an Executive Assistant. Kim graduated from Governor's State University in 1997 with a B.A. in business administration with a concentration in human resources. In 2007, she earned a MBA from Wesley College. Kim Smith's teaching experience at Alabama State includes: marketing, human resources, organizational behavior, and business communication.

\section{REFERENCES}

1. $\quad$ Absenteeism. (2006). American Heritage ${ }^{\circledR}$ Dictionary of the English Language. Retrieved from http://www.answers.com/topic/absenteeism\#ixzz1EZ01Pgqc

2. Berfield, S. (n.d.). Interview by S. Berfield [Video recording].Unmotivated, Anxious, and in Limbo: Suffering from Great Recession anxiety. Retrieved from http://feedroom.businessweek.com/index.jsp?fr_story=3466ab6f5e2c2b314df5a96740bdd70549eb5740

3. Bilski, J. (2010, July 23). Most firms have multiple stress-relief programs: How many does yours offer? Retrieved from http://www.cfodailynews.com

4. Bilski, J. (2008, November 11). Do wellness programs work? Let the numbers answer that. Retrieved from http://www.cfodailynews.com

5. Boyles, S. (2009, September 11). Migraines reduce workplace productivity. WebMD Health News. Retrieved from http://www.medicinenet.com/script/main/art.asp?articlekey=105524

6. Clements, A. (2008, April 1). Stress Survey 2008 - Get a grip on your stressed out staff workers workplace. 
Retrieved from http://www.humanresourcesmagazine.com/news/796383/Workplace-Stress-Survey-2008--grip-stressed-out-staff-workers-workplace/

7. Corporate Executive Board. (2009, March 27). The increasing call for work-life balance. Bloomberg Businessweek. Retrieved from http://www.businessweek.com/managing/content/mar2009/ca20090327_734197.htm

8. Cyboran, S. \& Morrison, T.M. (2006, November 12). Paid time off: Giving employees more control over leave. SHRM.org. Retrieved from http://www.shrm.org/hrdisciplines/benefits/Articles/Pages/CMS_018373.aspx

9. FMLA claims rise by more than $10 \%$ in 2010. (2010, November 24). What's Working in Human Resources, 6.

10. Goodman, M. (2010, February 18). Work overload brings panic, anxiety, stress: The more demanding recession-crunched jobs become, the more health problems ensue. Retrieved from http://abcnews.go.com/Business/work-overload-brings-panic-anxiety-stress/story?id9868689\&page=1

11. Greenberg, J. (2011). Coping with Organizational Life: Emotions and Stress. In Behavior in Organizations. (pp. 142-175). Upper Saddle River, NJ: Prentice Hall.

12. Gurchiek, K. (2009, February 2). Managers, employees view presenteeism differently. HR News. Retrieved from http://www.shrm.org/Publications/HRNews/Pages/ViewPresenteeismDifferently.aspx

13. Gurchiek, K. (2008, August 15). Economic woes hit female workers particularly hard. HR News. Retrieved from http://www.allbusiness.com/government/government-bodies-offices-legislative/11658007-1.html

14. Hall, C. (2010, October 6). The hidden cost of absenteeism: New workplace options absence tracking helps businesses mitigate missed work. Retrieved from http://www.workplaceoptions.com

15. Immen, W. (2009, June 12). Feeling sick? Booking off is better for your career. The Globe and Mail, p. B15. Retrieved from: http://proquest.umi.com/pqdweb?index

16. Introduction to Attendance Management. (2010, March). Attendance Management - working together. Retrieved from: http://www.benefits.org/interface/cost/absent.htm

17. Kim, J., Sorhaindo, B., \& Garman, E. T. (2006, June 20). Relationship between financial stress and workplace absenteeism of credit counseling clients. Journal of Family and Economic Issues, 27(3), 458478. DOI:10.1007/s10834-006-90024-9.

18. Middaugh, D.J. (2007, April 1). Presenteeism: Sick and tired at work. Dermatology Nursing; 19(2), 172185 .

19. Miller, S. (2009, June). Most employers underestimate health impact on productivity. HR Magazine, 54(6). p. 20. Retrieved from http://www.shrm.org/hrdisciplines/benefits/Articles/Pages/ImpactonProductivity.aspx

20. Miller, S. (2007, October) Depression intervention: Telephone counseling increases worker productivity. SHRM.org Retrieved from http://shrm.org/hrdisciplines/benefits/Articles/Pages/CMS_023215.aspx

21. More workers call out sick when they're well. (2010, November 24) What's Working in Human Resources, 6.

22. National Survey of U.S. CFOs finds nearly one-third targeting healthcare cutbacks for their workforce. Greatest pricing pressure is employee benefits relating to healthcare and pensions. (2010, November 1). Retrieved from http://www.grantthornton.com/portal/site/gtcom/menuitem.550794734a67d883a5f2ba40633841ca/?vgnext oid=96820b6d7bdfb210VgnVCM1000003a8314acRCRD\&vgnextchannel=f51ecbbdad9c4010VgnVCM10 0000368314acRCRD

23. One-third of firms to cut healthcare costs: Employee benefits top lists of pricing pressure points. (2010, November 24). What's Working in Human Resources, 1.

24. Paton, N. (2008, December). Economic downturn continues to put employee health at risk. Occupational Health. Sutton. 60(12), 5.

25. Presenteeism. (n.d.). Dictionary.com Unabridged. Retrieved from Dictionary.com website: http://dictionary.reference.com/browse/presenteeism

26. Preidt, R. (2010, October 8). Obesity among U.S. workers has hefty price tag: Study. Bloomberg Businessweek. Retrieved from http://www.businessweek.com/lifestyle/content/healthday/644073.html

27. Preidt, R. (2009, May 13). Productivity takes a hit from obesity, diabetes. Bloomberg Businessweek. Retrieved from http://www.businessweek.com/lifestyle/content/healthday/626770.html

28. Rankin, D. (2010, August 23). Lower costs and raise productivity in your business by improving 
employees' mental health. Retrieved from http://ezinearticles.com

29. Schultz, A. B., Chen, C., \& Edington, D.W. (2009). The cost and impact of health conditions on presenteeism to employers: a review of the literature. Pharmacoeconomics, 27(5). 365-378.

30. $\quad$ Sick Time Means a Healthier Economy. (2009, June 7). St. Petersburg Times. p.2.

31. Society for Human Resource Management. (2009, January 12). Omnibus Employee Survey. [PowerPoint Presentation] Retrieved from: www.shrm.org/Research/SurveyFindings/Articles/Documents/OE\%20$\% 20$ econ\%20data.ppt $\cdot$ PPT file.

32. Tyson, B. (2010, October 30). How Does Stress Affect Attitudes and Behavior in Work Settings? Retrieved from http://www.brighthub.com/office/career-planning/articles/93650.aspx\#ixzz1F8QVfFGN

33. U.S. Congress Joint Economic Committee. (2010, August). Women and the Economy 2010: 25 Years of Progress But Challenges Remain [Report]. Retrieved from http://jec.senate.gov/public/?a=Files.Serve\&File id=8be22cb0-8ed0-4a1a-841b-aa91dc55fa81

34. Walton, R. (2011, February 23). Jack Welch talks up innovation at Mabee Center forum Original Print Headline: Welch offers advice. Retrieved from http://www.tulsaworld.com/business/article.aspx?subjectid=49\&articleid=20110223 49_E1_ULNSom672 $\underline{498}$

35. Weaver, R. (2010, June 8). Cost of presenteeism surpasses absenteeism. Retrieved from http://www.examiner.com/human-capital-in-detroit/cost-of-presenteeism-surpasses-absenteeism

36. Wells, S. J. (2010, October 1). Obesity in the workplace: Employers' concern runs high. HRMagazine, 55(10). Retrieved from http://www.shrm.org/Publications/hrmagazine/EditorialContent/2010/1010/Pages/1010wells1.aspx

37. Wojcik, J. (2009, December). Most employers aren't combating workplace stress. Retrieved from http://www.workforce.com/archive/feature/benefits-compensation/most-employers-arent-combatingworkplace-stress/index.php 